\title{
Anatomical Variability in the Termination of the Basilar Artery in the Human Cadaveric Brain
}

\author{
Insan Kadavra Beyninde Baziller Arter Sonlanmasmmn Anatomik \\ Değişkenliği
}

Sandhya GUNNAL, Mujeebuddin FAROOQUI, Rajendra WABALE

Rural Medical College, Department of Anatomy, Post. Loni, Tal. Rahata, Dist. Ahmednagar, Maharashtra, India

Corresponding Author: Sandhya A GUNNAL / E-mail: sandhyagunnal@gmail.com

\begin{abstract}
AIM: The basilar artery (BA) is the prominent median vessel of the vertebrobasilar circulation and usually terminates into two posterior cerebral arteries forming the posterior angle of the Circle of Willis (CW). To tackle different variations of CW, basilar artery acts as a guideline for neuroradiologists and neurosurgeons. Basilar termination is the most frequent site of aneurysm. Abnormalities at the site of termination may compress the oculomotor nerve. Variations at the termination may complicate surgeries at the base of brain. The present study aims to add to the knowledge regarding the termination pattern of the BA.

MATERIAL and METHODS: 170 BA terminations were studied. Morphological variations in the termination pattern were noted. Frequency of variations in termination patterns was recorded. Dimensions of BA were measured. Data were analyzed.

RESULTS: Morphological variations in termination were seen in $17.64 \%$. Bifurcation, Trifurcation, Quadrifurcation, Pentafurcation and Nonfurcation of BA was seen in $82.35 \%, 5.29 \%, 5.88 \%, 3.52 \%$ and $2.94 \%$ respectively. BA associated with aneurysm and Fenestration was seen in $3.52 \%$ and $1.17 \%$ respectively. Mean length and diameter of $B A$ was $30.27 \mathrm{~mm}$ and $4.8 \mathrm{~mm}$ respectively.
\end{abstract}

CONCLUSION: Awareness of these anatomical variations in termination patterns of BA is important in neurovascular procedures.

KEYWORDS: Basilar artery, Bifurcation, Trifurcation, Pentafurcation, Variation, Brain, Anatomy

öz

AMAÇ: Baziller arter (BA), vertebrobaziller dolaşımın önde gelen median damarıdır ve genellikle iki posterior serebral arter halinde sonlanıp Willis Poligonunun (CW) posterior açısını oluşturur. Baziller arter, farklı CW varyasyonlarını ele almak açısından, nöroradyologlar ve nöroşirürjiyenler için bir kılavuz görevi görür. Baziller terminasyon, anevrizmanın en sık görüldüğü bölgedir. Terminasyon bölgesindeki anormallikler okülomotor siniri sıkıştırabilir. Terminasyondaki varyasyonlar beyin tabanındaki cerrahilerde komplikasyon oluşturabilir. Mevcut çalışma, BA terminasyon paterniyle ilgili bilgiye katkıda bulunmayı hedeflemektedir.

YÖNTEM ve GEREÇLER: 170 BA terminasyonu çalışıımıştır. Terminasyon paternindeki morfolojik değişiklikler kaydedilmiştir. Terminasyon paternlerindeki varyasyonların sıklığı kaydedilmiştir. BA boyutları ölçülmüştür. Veriler analiz edilmiştir.

BULGULAR: Terminasyonda morfolojik varyasyonlar \%17,64 olguda görülmüştür. Bifurkasyon, Trifurkasyon, Kuadrifurkasyon, Pentafurkasyon ve Nonfurkasyon BA'da sırasıyla \%82,35, \%5,29, \%5,88, \%3,52 ve \%2,94 sıklığında görülmüştür. Anevrizma ve Fenestrasyonla ilişkili BA sırasıyla $\% 3,52$ ve \%1,17 sıklığında görülmüştür. BA ortalama uzunluk ve çapı sırasıyla 30,27 mm ve 4,8 mm bulunmuştur.

SONUÇ: Nörovasküler işlemler sırasında BA terminasyon paternlerinde bu anatomik varyasyonların farkında olma önemlidir.

ANAHTAR SÖZCÜKLER: Baziller arter, Bifurkasyon, Trifurkasyon, Pentafurkasyon, Varyasyon, Beyin, Anatomi

\section{INTRODUCTION}

The basilar artery (BA) is formed by the union of the vertebral arteries (VA), in the pontine cistern. It follows a shallow median groove on the ventral surface of pons (18). The artery is the large, prominent, median vessel, and forms the spine of the vertebrobasilar circulation. The artery usually terminates by dividing into two posterior cerebral arteries. This point of termination of the basilar artery forms the posterior angle of the Circle of Willis (CW) (7). CW shows considerable variations at the base of brain. The study was undertaken to look at different variations of $C W$. The basilar artery acts as a guideline for anatomists, neuroradiologists and neurosurgeons. The basilar termination is the most frequent site of aneurysm (20). Abnormalities at the site of termination may compress the oculomotor nerve (19). Variations at the termination may complicate surgery at the base of brain. The present study therefore aims to add to the knowledge regarding the termination pattern of the basilar artery (4).

\section{MATERIAL and METHODS}

The study was conducted at the department of Anatomy, Rural Medical College, PIMS, Loni. The study was started by undertaking the institutional ethical clearance (PIMS/PhD/ $\mathrm{RC} / 2013 / 28$ ). A total of 170 formalin preserved brains of 
human cadavers were examined. The brains obtained from cadaveric bodies were of unknown age and with unknown cause of death. The brains with the gross morphological variations were excluded from the study. Arachnoid mater in the pontine cistern as well as in the interpeduncular fossa was removed carefully to expose the basilar artery and the posterior portion of CW. The basilar artery was identified and dissected completely from its origin to its termination. All the branches arising from basilar artery were dissected carefully. Special attention was given to the Posterior cerebral arteries (PCA) and Superior cerebral arteries (SCA). The branching pattern of the terminal part of the basilar artery was noted, well photographed and documented.

The arterial networks of the $\mathrm{CW}$ along with the termination of basilar artery and PCA, SCA and all possible small arteries at the termination of basilar artery of both sides were carefully and delicately separated from brain tissue and pasted on black plastic sheets for better view and for future reference. Morphological variations at the terminal portion of the basilar artery were well photographed again with a Canon digital camera with a resolution of 10 mega pixel. Dimensions of the basilar artery were measured with the vernier caliper with a smallest count of $0.01 \mathrm{~mm}$. Data collected in the study were analyzed to calculate the mean, standard deviation and percentages.

\section{RESULTS}

The different patterns of termination of basilar artery were studied in detail and classified as the bifurcation, trifurcation, quadrifurcation, pentafurcation and nonfurcation. The incidence of the different patterns of termination of BA is tabulated in Table I.

Bifurcation of basilar artery: The basilar artery terminates into 2 PCA. Bifurcation was the most commonly seen pattern and found in 140 (82.35\%) cases (Figure 1A). Along with this usual bifurcation, we found 3 unusual cases of bifurcation of the basilar artery in the present study as the PCA and SCA arising from a common trunk (CT). CT was bilateral. It looked like early bifurcation of the basilar artery before the origin of the SCAs (Figure 1B).

Standard conventional termination observed was the bifurcation of basilar artery. Morphological variations in termination were seen in 30 cases (17.64\%).

Trifurcation of basilar artery: In this pattern there were 3 arteries arising from the terminal point of the basilar artery. (Figure 2A) Trifurcation of basilar artery was found in 9 cases (5.29\%). Trifurcation was divided into Type A, Type B and Type $C$. This division was according to the branching pattern in the formation of trifurcation.

In type A trifurcation, there were 2 PCAs and 1 SCA. In this pattern, 2 SCAs of the opposite side were arising at a different level from the basilar artery, one SCA at the regular site and one at the termination of the basilar artery. This pattern was termed as trifurcation type $A$ and was seen in 4 cases (Figure 2 B).

Table I: Different Patterns of Termination of BA

\begin{tabular}{|c|l|r|r|} 
Sr. No. & $\begin{array}{l}\text { Termination } \\
\text { patterns of BA }\end{array}$ & No. of cases & Percentage \\
\hline 1 & Bifurcation & 140 & 82.35 \\
\hline 2 & Trifurcation & 9 & 5.29 \\
\hline 3 & Quadrifurcation & 10 & 5.88 \\
\hline 5 & Pentafurcation of & 6 & 3.52 \\
\hline
\end{tabular}

\section{Bifurcation of BA 140 (82.35\%)}
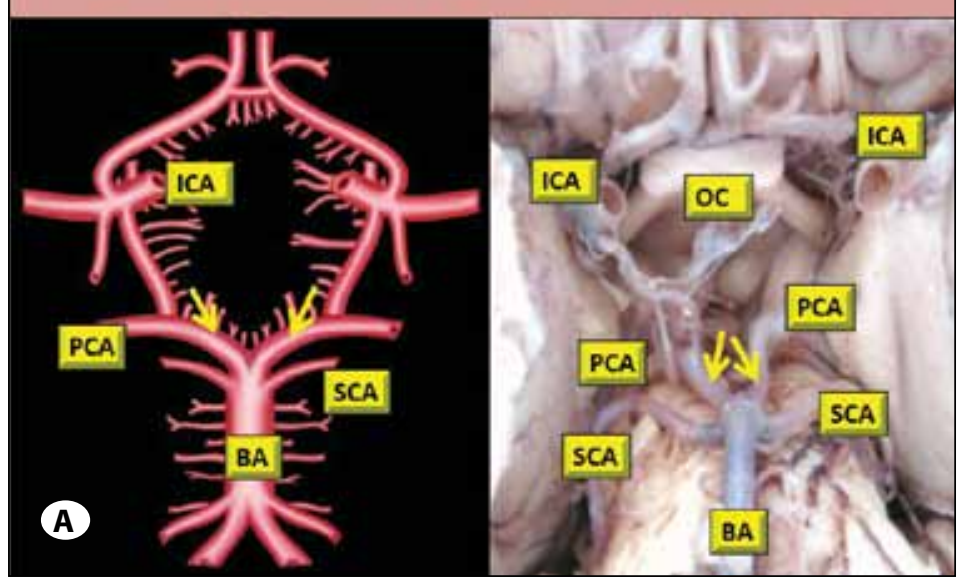

\section{Bifurcation of BA with $\mathrm{CT}$}

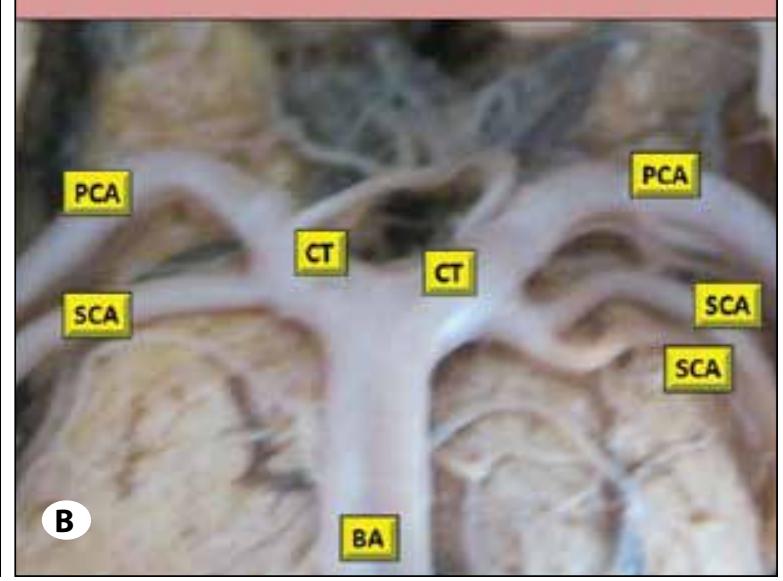

Figure 1: A) Standard Bifurcation of basilar artery. Left side: Schematic diagram, Right side: Actual specimen from the present study, Arrows: Arteries taking part in termination. BA- Basilar artery, PCA- Posterior cerebral artery, SCA- Superior cerebellar artery, ICA- Internal Carotid Artery, OC- Optic chiasm. B) Bifurcation of BA with Common Trunk for PCA and SCA. BA- Basilar artery, CTCommon trunk, PCA- Posterior cerebral artery, SCA- Superior cerebellar artery. 
In type $B$ trifurcation, the 3 terminal branches were 1 PCA, 1 SCA and 1 common trunk (CT) at the other side of the PCA and SCA. This pattern was termed as trifurcation type $B$ and was seen in 3 cases (Figure $2 \mathrm{C}$ ).

In type $C$ trifurcation, the 3 terminal branches were 2 PCAs, and one Posterior communicating artery (PoCA). In this pattern, the PoCA was connecting the ICA directly to the basilar artery termination. This pattern was termed as trifurcation type $C$. It was seen in 2 cases. In both cases it was seen on left side (Figure 2 D).

Quadrifurcation of basilar artery: This pattern showed 4 branches arising from the termination of the basilar artery. There were 2 PCA and 2 SCA arising from the same point of termination of the basilar artery. The origin of SCA shifted higher up to the termination of the basilar artery. Quadrifurcation of basilar artery was found in 10 cases (5.88 \%) (Figure 3A, B).
Pentafurcation of basilar artery: Pentafurcation showed 5 branches arising from the termination of basilar artery. Five contributing branches in the pentafurcation were the 2 PCAs and 3 SCAs arising from the same terminal point of the basilar artery (on one side SCA had duplication). Pentafurcation of basilar artery was found in 6 cases (3.52\%) (Figure 4A, B).

Nonfurcation of basilar artery: In nonfurcation, there was direct continuation of the basilar artery in to a single PCA, either of the right or left side. This pattern suggests aplasia of one of the PCA. Nonfurcation was found in 5 cases (2.94\%) (Figure 5A). In one case both PCA were present, but the origin of one of the PCA was shifted below at the level of the origin of the SCA, suggesting that PCA was the lateral branch of basilar artery and not the terminal branch (Figure 5B).

The aneurysms and fenestrations were also examined.
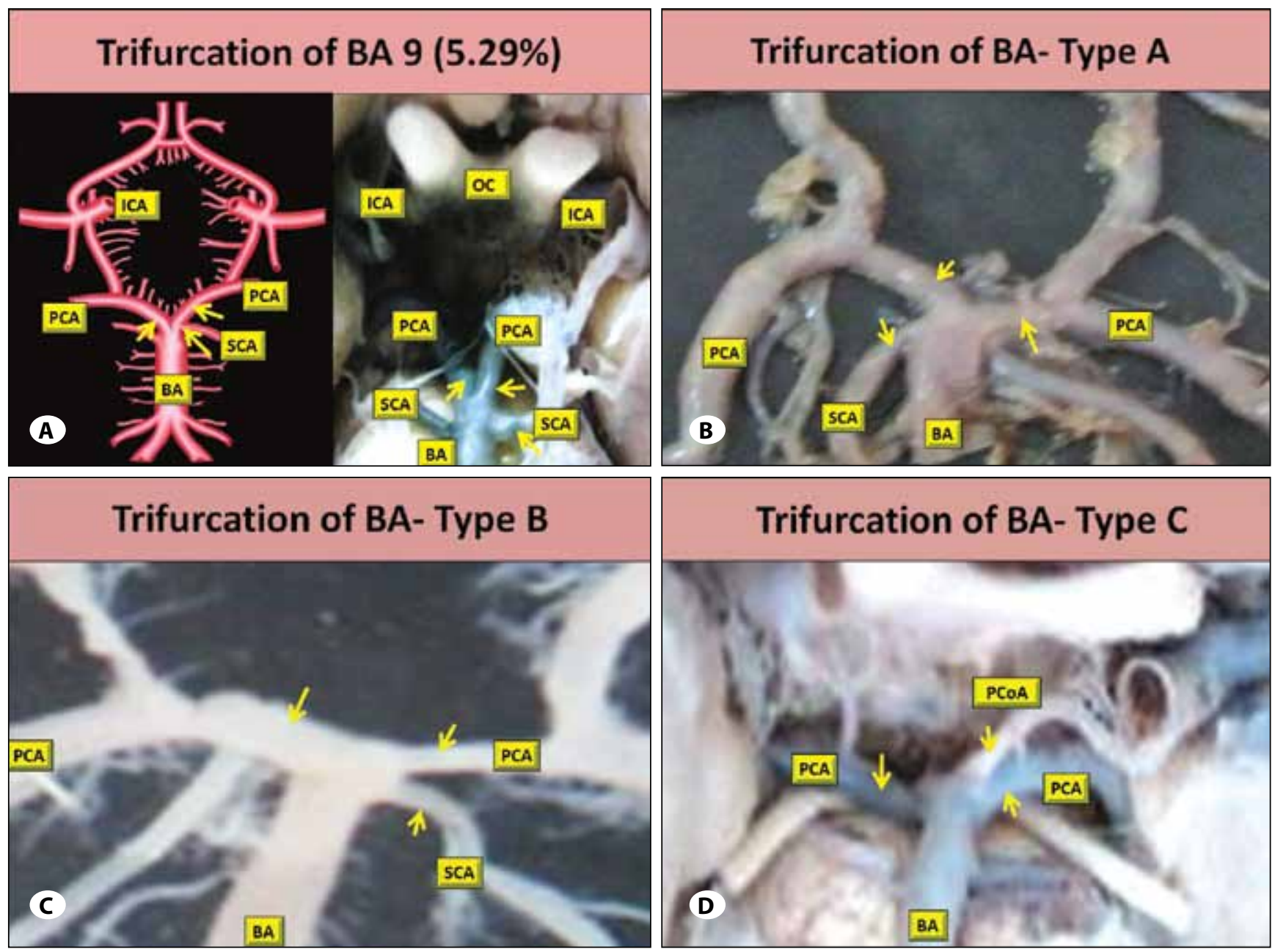

Figure 2: A) Trifurcation of BA. Left side: Schematic diagram, Right side: Actual specimen found in the present study, Arrows: Arteries taking part in termination. BA- Basilar artery, PCA- Posterior cerebral artery, SCA- Superior cerebellar artery, ICA- Internal Carotid Artery, OC- Optic chiasm. B) Trifurcation Type A, Arrows: Arteries taking part in termination. BA- Basilar artery, PCA- Posterior cerebral artery, SCA- Superior cerebellar artery. C) Trifurcation Type B. Arrows: Arteries taking part in termination. BA- Basilar artery, PCAPosterior cerebral artery, SCA-Superior cerebellar artery. D) Trifurcation Type C. Arrows: Arteries taking part in termination. BA- Basilar artery, PCA- Posterior cerebral artery, PCoA- Posterior communicating artery. 
Aneurysm: Apart from termination patterns of basilar artery in the present study, an aneurysm at the site of termination was noticed in 6 cases (3.52\%) (Figure 6A).

Fenestration: Fenestration was observed at the site of termination adjoining the right PCA in two specimens (1.17\%) (Figure 6B).

Morphometry: Morphometric data of the basilar artery were measured and tabulated in Table II.

The length of the basilar artery was measured from its origin to its termination. It ranged from $24.6 \mathrm{~mm}$ to $35 \mathrm{~mm}$ with a mean of $30.27 \mathrm{~mm} \pm 3.5 \mathrm{SD}$.

Diameter of the basilar artery at its middle was measured. It ranged from 3 to $6 \mathrm{~mm}$ with the mean of $4.8 \mathrm{~mm} \pm 0.7 \mathrm{SD}$.
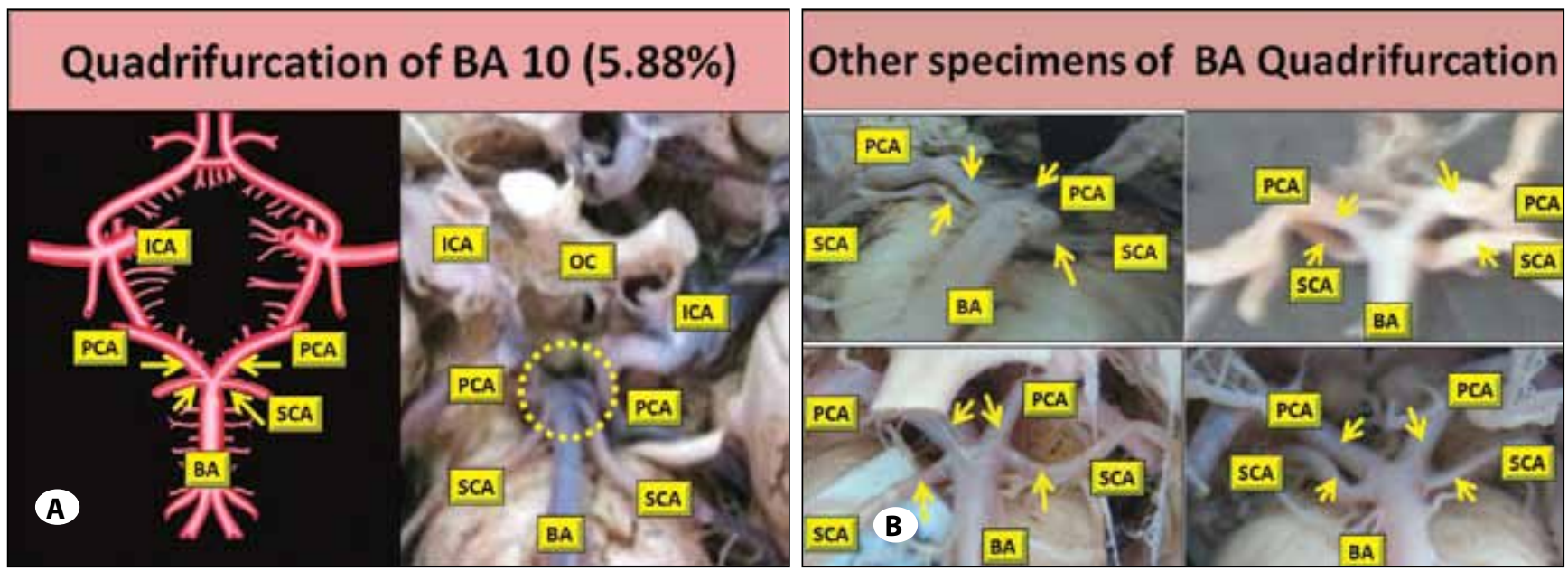

Figure 3: A) Quadrifurcation of basilar artery. Left side: Schematic diagram, Right side: Actual specimen found in the present study, Arrows and dotted circle: Arteries taking part in termination. BA- Basilar artery, PCA- Posterior cerebral artery, SCA- Superior cerebellar artery, ICA- Internal Carotid Artery, OC- Optic chiasm. B) Other specimens of Quadrifurcation of Basilar Artery. Arrows: Arteries taking part in termination. BA- Basilar artery, PCA- Posterior cerebral artery, SCA- Superior cerebellar artery,

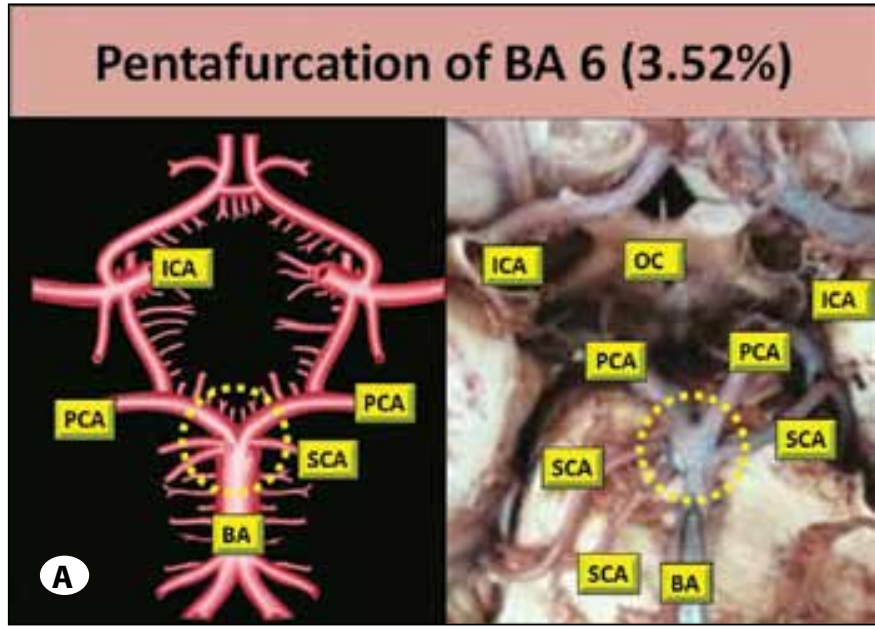

\section{Other specimens of BA Pentafurcation}

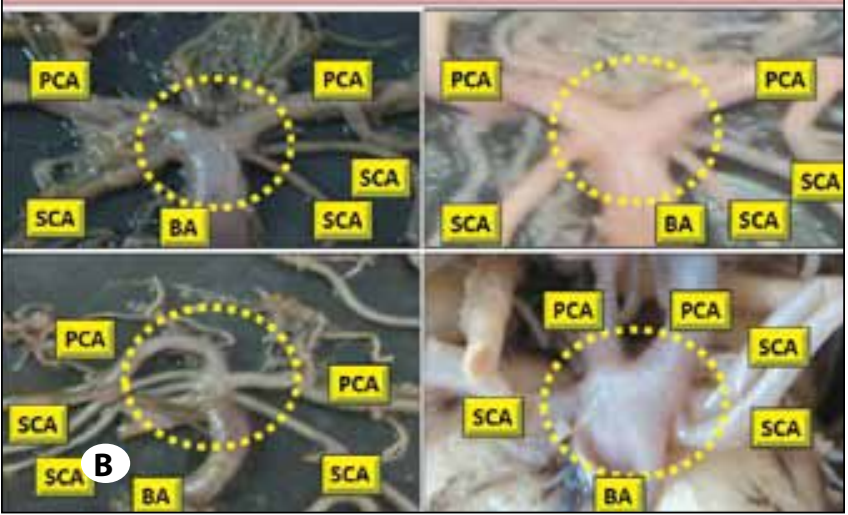

Figure 4: A) Pentafurcation of basilar artery. Left side: Schematic diagram, Right side: Actual specimen found in the present study, Dotted circle: Arteries taking part in termination. BA- Basilar artery, PCA- Posterior cerebral artery, SCA- Superior cerebellar artery, ICA- Internal Carotid Artery, OC- Optic chiasm. B) Other specimens of Pentafurcation of BA. Dotted circle: Arteries taking part in termination. BA- Basilar artery, PCA- Posterior cerebral artery, SCA- Superior cerebellar artery, ICA- Internal Carotid Artery, OC- Optic chiasm. 
There are very few reports on variant termination of the basilar artery. However, Ogengo et al. have done a detailed study on the termination of the basilar artery on 173 cadaveric brains and observed Bifurcation, Trifurcation, Quadrifurcation and Pentafurcation in 82, 10, 6 and 2 percent respectively (13). These termination patterns were found in 82.3, 5.2, 5.8 and 3.5 percent in the present study. In addition, the present study we also found the direct continuation of the basilar artery into a single PCA due to aplasia of the opposite PCA, named as Nonfurcation of basilar artery. This pattern was present

Table II: Morphometry of BA (millimeters)

\begin{tabular}{|l|c|c|c|c|}
\hline BA & Minimum & Maximum & Average & SD \\
\hline Length & 24.6 & 35 & 30.27 & 3.50 \\
\hline Diameter & 3 & 6 & 4.8 & 0.07 \\
\hline
\end{tabular}

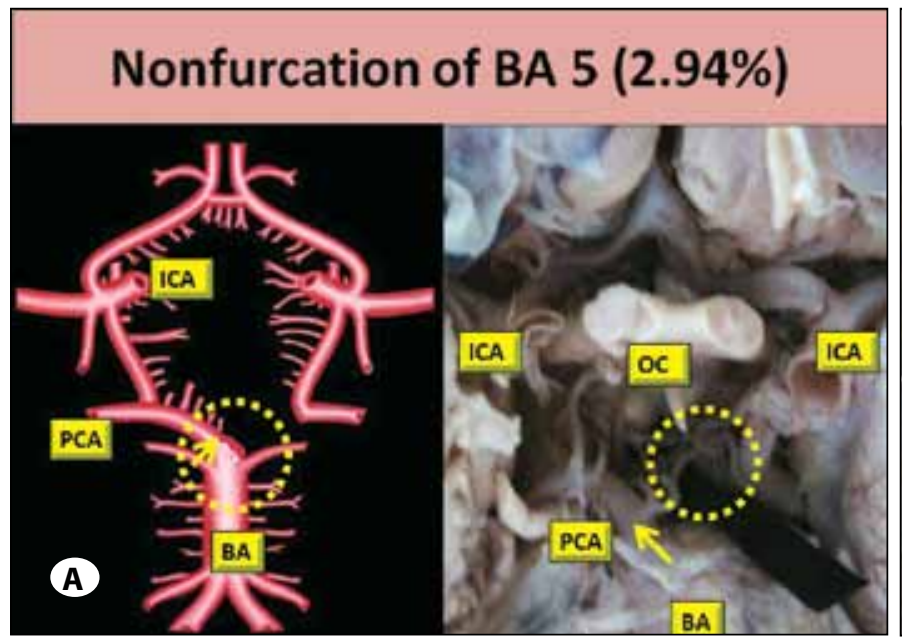

in $2.9 \%$. However the variant patterns, namely trifurcation, quadrifurcation and pentafurcation, are hardly reported in the literature.

Gabella reported the incidence of bifurcation as $80 \%$ (3). This frequency is comparable with the present study.

Bala et al. reported one case of trifurcation where the SCA was arising from the P1 segment of the PCA instead of the basilar artery on right side (2). It was like Type $B$ trifurcation of the present study. This type of variation had been also reported earlier by McCullough (0.14\%) and Caruso et al. (1\%) as a rare variation $(3,12)$. The incidence of trifurcation was $5.29 \%$ in the present study, which is much higher than the above mentioned 3 authors but lower than that of the results of Ogengo et al. (13). The present study suggests that these variations are not so rare. The quadrifurcation of basilar artery was the commonest variation seen in the present study.

\section{Other specimens of Nonfurcation of BA}
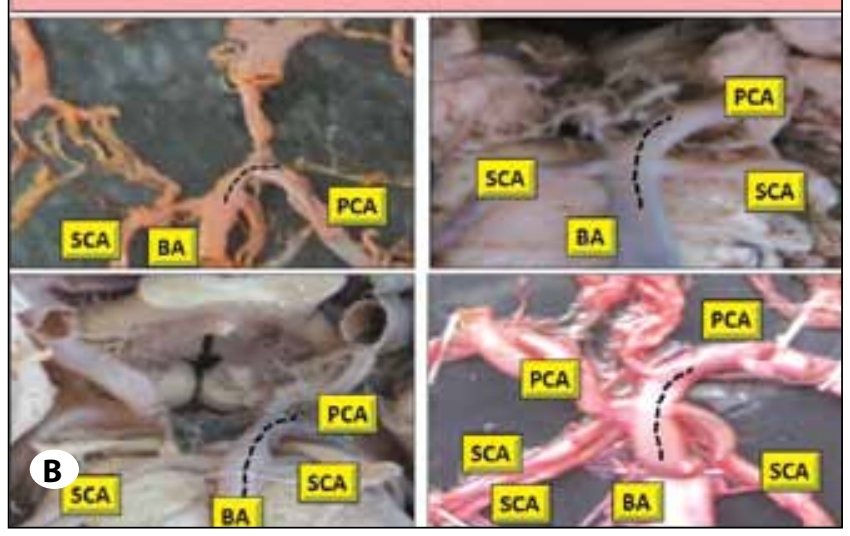

Figure 5: A) Nonfurcation of basilar artery. Left side: Schematic diagram, Right side: Actual specimen found in the present study, Arrow shows continuation of BA into a single PCA. BA- Basilar artery, PCA- Posterior cerebral artery, SCA- Superior cerebellar artery, ICA- Internal Carotid Artery, OC- Optic chiasm. B) Other specimens of Nonfurcation of BA. Dotted line shows continuation of BA into a single PCA. BA- Basilar artery, PCA- Posterior cerebral artery, SCA- Superior cerebellar artery, ICA- Internal Carotid Artery, OC- Optic chiasm.

\section{Aneurysm of BA $6(3.52 \%)$}

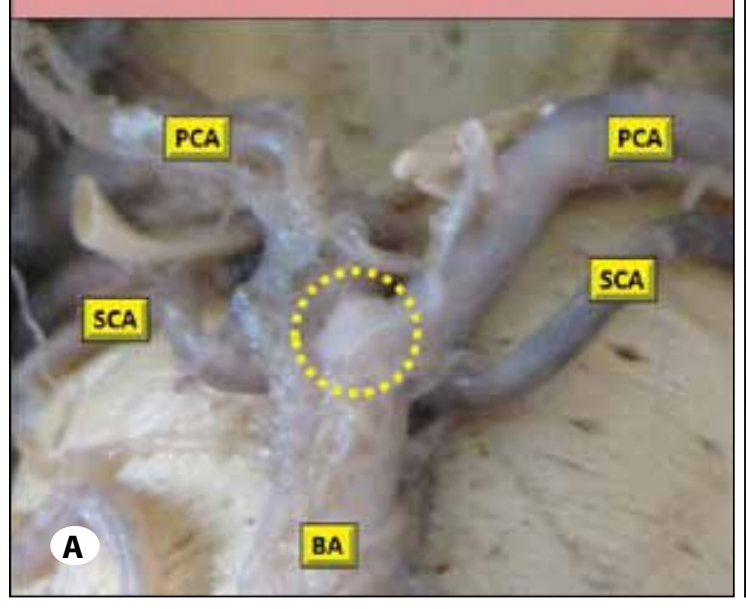

\section{Fenestration of BA 2 (1.17\%)}

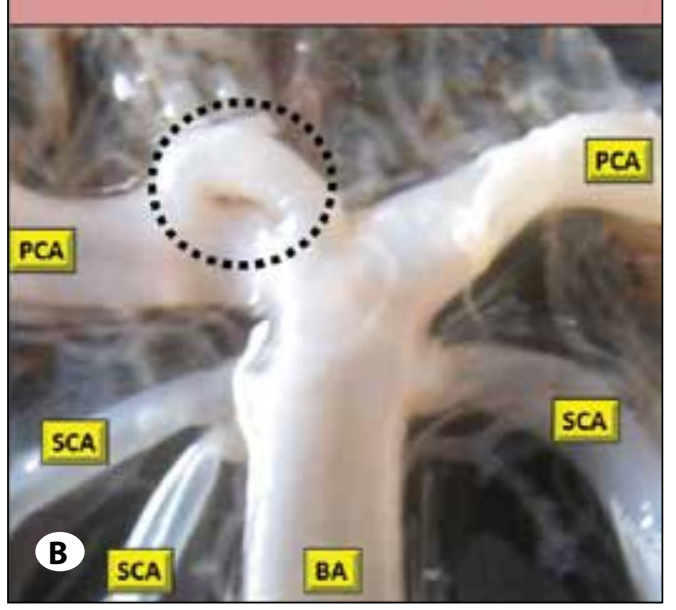

Figure 6: A) Aneurysm of basilar artery.

Dotted circle:

Aneurysm of BA at termination, BA- Basilar artery, PCA- Posterior cerebral artery, SCASuperior cerebellar artery. B) Fenestration at Basilar artery termination. Dotted circle: Fenestration at $\mathrm{BA}$ at termination, BA- Basilar artery, PCA- Posterior cerebral artery, SCA-Superior cerebellar artery. 
The existence of such variations can also be explained on a developmental basis.

Padget described embryogenesis of the cerebral circulation. It may be helpful to understand different variations in the termination pattern of the basilar artery. In the primitive stage of the $4 \mathrm{~mm}$ sized embryo, the vertebral arteries develop from a pair of primitive longitudinal arteries present lateral to the primitive hindbrain. Fusion of bilateral plexiform longitudinal neural arteries forms a single basilar artery. Midline fusion occurs in a caudo-cranial manner $(11,15)$. Any change in the normal developmental pattern results in variations, which also play an important role in the development of aneurysmal vascular pathology (3).

The present study proposes the following embryological interpretations for different branching patterns of the basilar artery.

In our study, we observed various types of termination of basilar artery. These were bifurcation, trifurcation, quadrifurcation, pentafurcation and non-furcation. This mode of termination depends on the extent of fusion of the primitive longitudinal neural arteries and congruity of the two sides when the fusion begins.

When two primitive channels are congruent at the beginning of fusion, the mode of termination might be bifurcation or quadrifurcation depending on the extent of fusion. Incongruity of the two primitive channels at the beginning of fusion results in a mode of termination that is trifurcation or pentafurcation depending on the extent of fusion.

In the disturbance of the process of union of the two arteries, the following variations may occur depending upon the extent and congruence.

Primitive longitudinal neural arteries join together in the caudo-cranial direction to form the basilar artery. If the terminal point of fusion of the two arteries is a little cranial to the origin of the SCA, there is the formation of basilar artery with standard bifurcation (Figure 7A-C).

If the terminal point of fusion of two arteries remain exactly at the origin of SCA, there will be the occurrence of quadrifurcation of basilar artery. This will be due to the nonunion of 2 arteries distal to the level of origin of the SCA (Figure 8A-C).

If the terminal point of fusion of the arteries still remains caudal or lower than the site of origin of the SCA, there will be a Bifurcation of basilar artery with a common trunk giving origin to both PCA and SCA (Figure 9A-C).

The connecting trunk (CT) forms an additional branching point for development of atheromatous lesions (6).

If there is cranial/caudal shift in one of the two primitive longitudinal neural arteries, it may develop incongruence. In the union of incongruent primitive longitudinal neural arteries, if the terminal point of fusion of one artery is exactly at the origin of the SCA, and the terminal point of fusion of other artery is cranial to the origin of the SCA, there will be the formation of trifurcation of type $A$ (Figure 10A-C).

In the union of incongruent primitive longitudinal neural arteries, if the terminal point of fusion of one artery is exactly at the origin of the SCA, and the terminal point of fusion of other artery is caudal to the origin of the SCA, there will be the formation of trifurcation of type $B$ (Figure 11A-C).

In pentafurcation of Basilar Artery, duplication of SCA on one side was observed. Duplication of SCA is thought to be due to the origin of the branches of the SCA such as the marginal artery arising directly from the basilar artery. Duplication of SCA is important in several respects. It forms an additional artery to maintain circulation when the main artery is occluded. Perforators from it are vulnerable to inadvertent

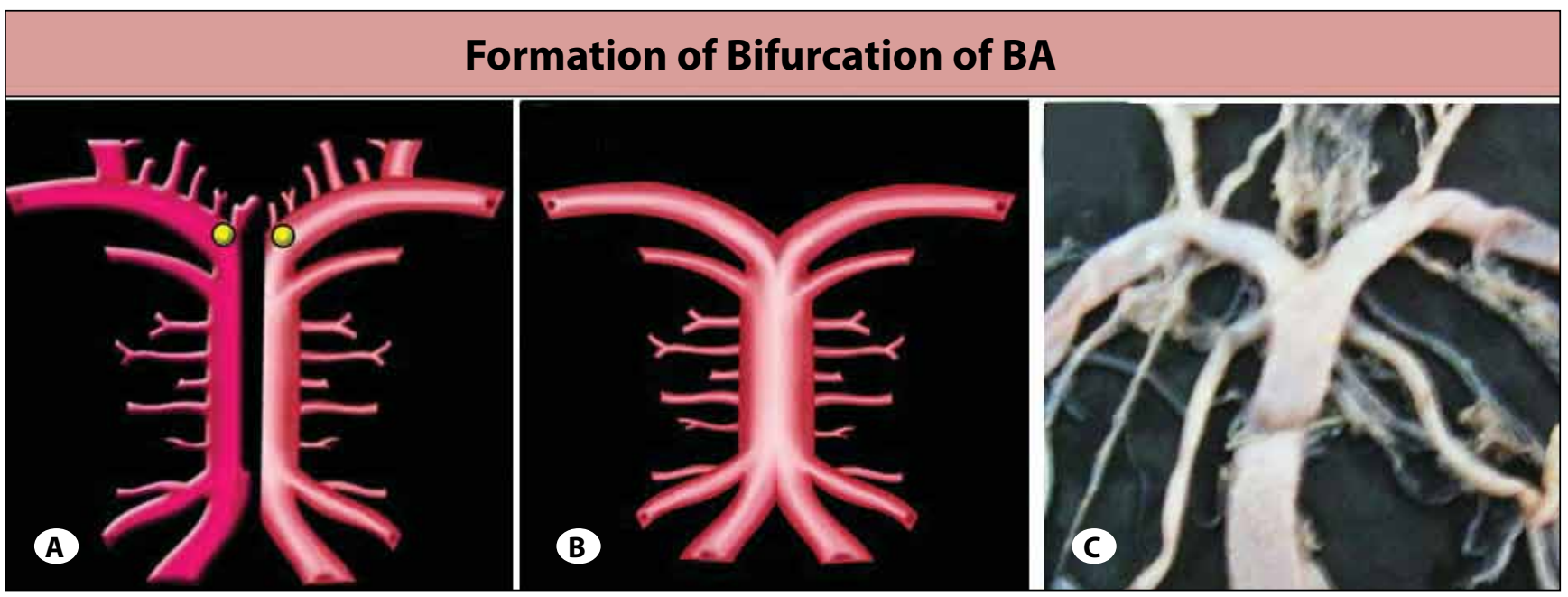

Figure 7: Formation of BA with standard bifurcation. A) Two Primitive longitudinal neural arteries, before fusion. Yellow dot on primitive arteries shows the terminal point of fusion. B) Fused Primitive longitudinal neural arteries to form BA. C) Specimen found in present study with standard bifurcation. 


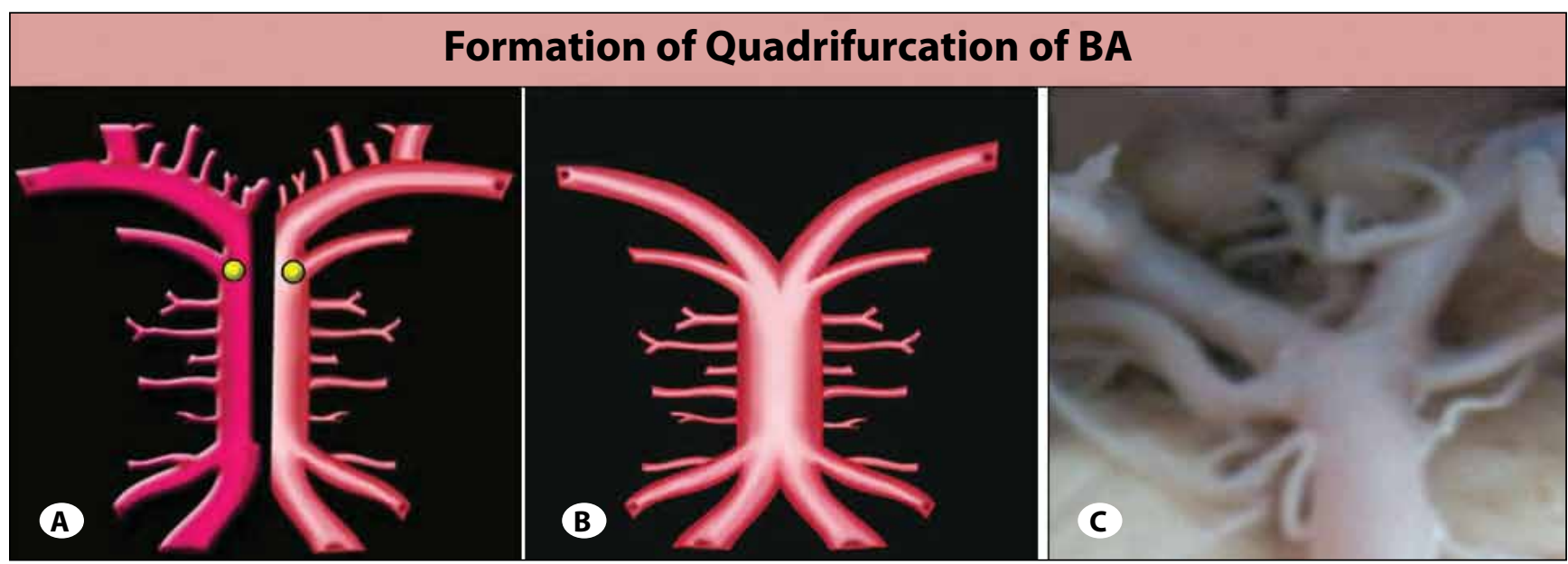

Figure 8: Formation of quadrifurcation of BA. A) Two Primitive longitudinal neural arteries, before fusion. Yellow dot on primitive arteries shows the terminal point of fusion. B) Fused Primitive longitudinal neural arteries to form BA with quadrifurcation. C) Specimen found in present study with quadrifurcation.

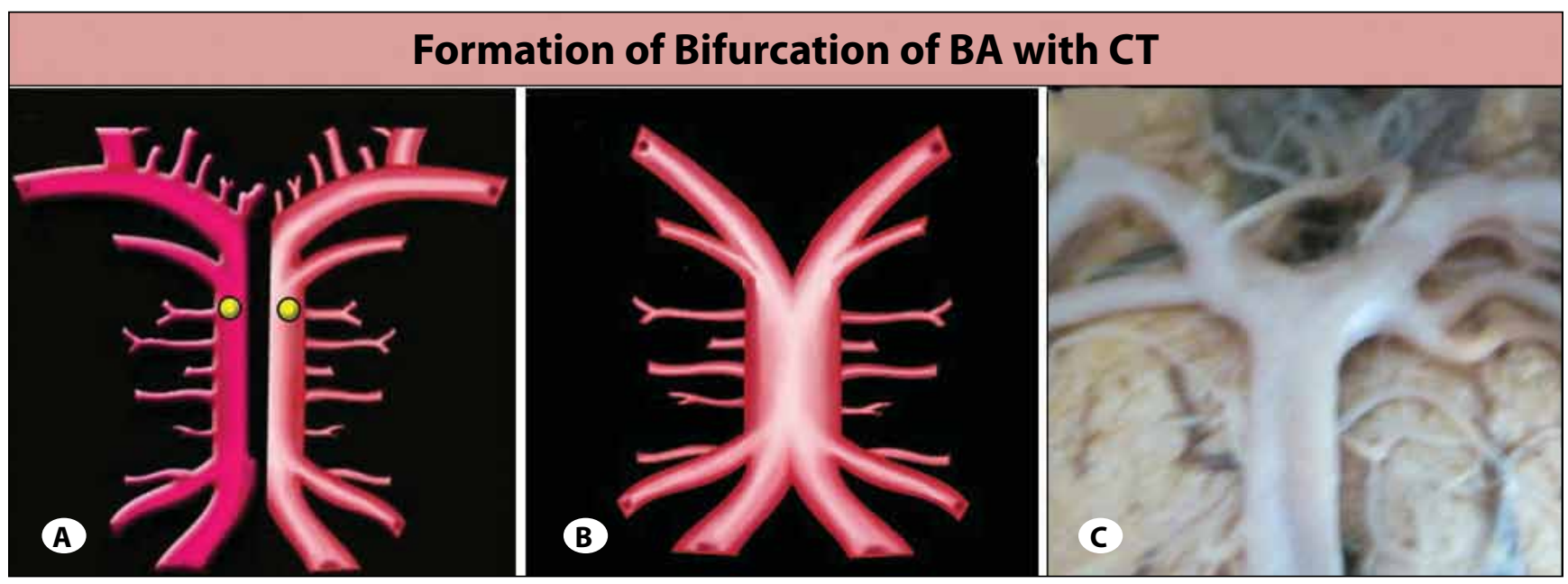

Figure 9: Formation of Bifurcation of BA with common trunk. A) Two Primitive longitudinal neural arteries, before fusion. Yellow dot on primitive arteries shows the terminal point of fusion. B) Fused Primitive longitudinal neural arteries to form BA with common trunk. C) Specimen found in present study with common trunk.

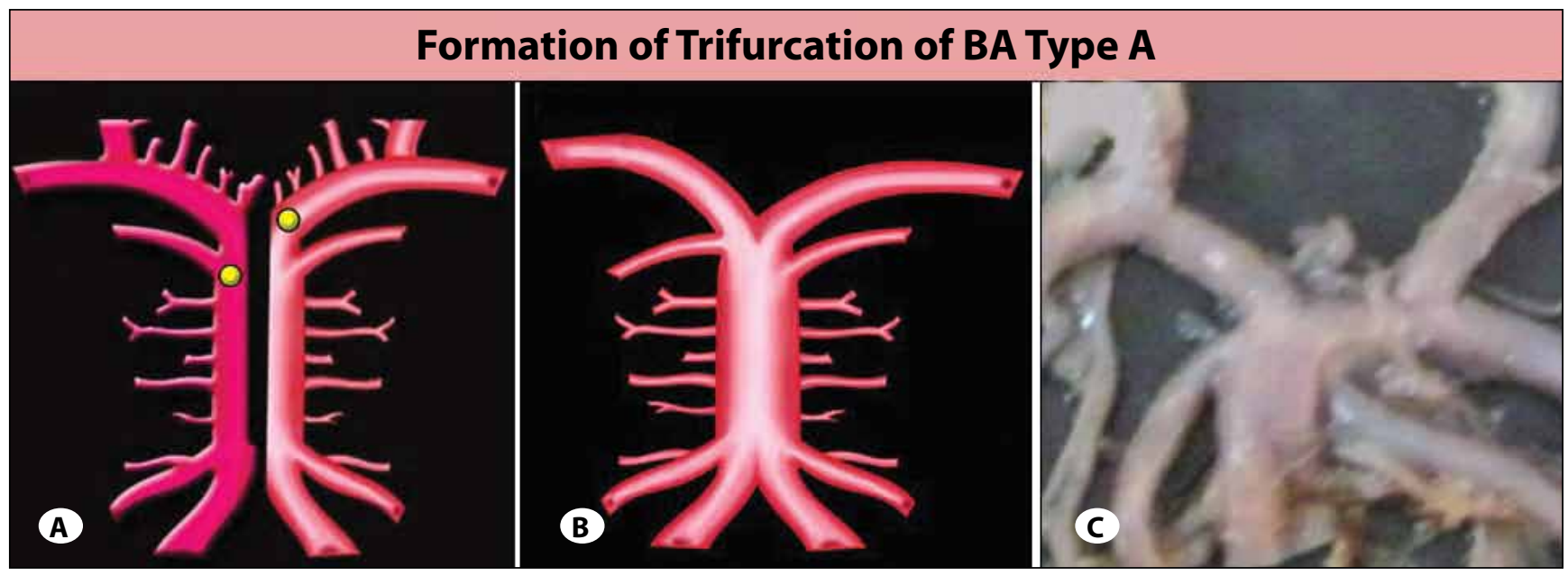

Figure 10: Formation of BA trifurcation- type A. A) Two Primitive longitudinal neural arteries, before fusion. Yellow dot on primitive arteries shows the terminal point of fusion. B) Fused incongruent primitive longitudinal neural arteries form BA trifurcation- type A. C) Specimen found in present study with BA trifurcation- type $A$. 
Table III: Comparison of Morphometry of BA in Millimeters

\begin{tabular}{|c|c|c|c|}
\hline Study & Year & No. of specimens & Length of the BA ( $\mathrm{mm})$ \\
\hline Adachi (1) & 1928 & 85 & $25-30$ \\
\hline Saeki and Rhoton (17) & 1977 & 50 & $15-40$ \\
\hline Kamath (10) & 1979 & 100 & $22-45$ \\
\hline Padmavathi et al. (16) & 2011 & 54 & $25-38$ \\
\hline Hosapatna M et al. (8) & 2012 & 20 & $25-37$ \\
\hline Present study & 2014 & 170 & $25-35$ \\
\hline
\end{tabular}

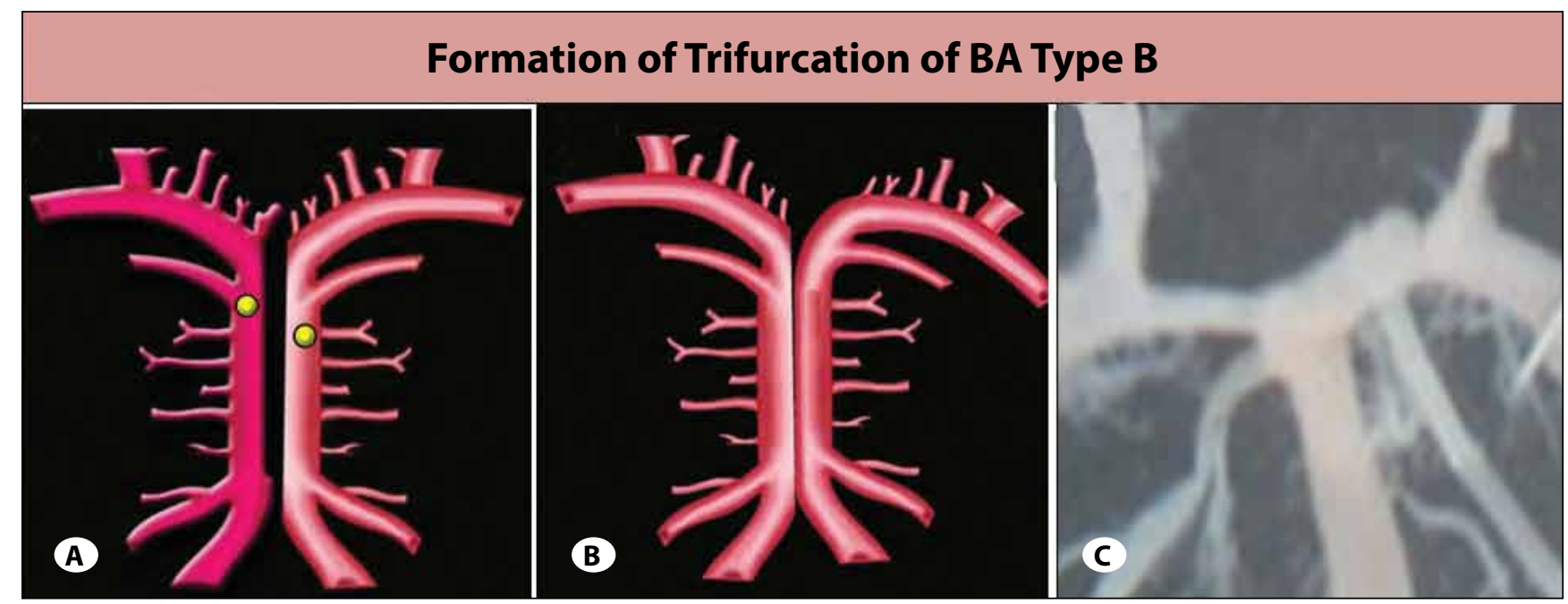

Figure 11: Formation of BA trifurcation- type B. A) Two Primitive longitudinal neural arteries, before fusion. Yellow dot on primitive arteries shows the terminal point of fusion. B) Fused incongruent primitive longitudinal neural arteries form BA trifurcation- type B. C)Specimen found in present study with BA trifurcation- type B.

injury during surgery (4). It may compress the oculomotor nerve.

'Nonfurcation' of basilar artery occurs due to the aplasia of the PCA of one side. The opposite PCA gets the contribution of both the primitive longitudinal neural arteries.

Aneurysm at the site of termination was observed in 6 cases (3.52\%).

Fenestration or segmental duplication is a rare congenital anomaly noticed in $1.17 \%$. A fenestration is a division of the arterial lumen resulting in two separate channels,

There are, however, few reports on the morphometry of the basilar artery. The results of the present study are compared with the previous studies in Table III.

\section{CONCLUSION}

In the present study classical bifurcation was seen in 140 cases $(82.35 \%)$. Variant branching patterns were seen in 30 cases (17.64\%). The term non-furcation of basilar artery was introduced for the first time in the study. Embryological interpretations for different branching patterns of basilar artery were proposed in the study. The present study has tried to contribute to the knowledge regarding the termination pattern of the basilar artery. Awareness of these anatomical variations in the termination patterns of the basilar artery is important for neurosurgeons and neuroradiologists in neurovascular procedures.

\section{REFERENCES}

1. Adachi B: Das Arteriensystem der Japaner. Kyoto: Verlag der Kaiserlich-Japanischen Universitat zu, Bd II, 1928

2. Bala M, Passi DK, Kaushal S: Microsurgical analysis of variations of the posterior segment of Circle of Wills. IJPAES 4(1):6-10, 2014

3. Caruso G, Vincentelli F, Rabehanta P, Giudicelli G, Griosoli F: Anomalies of the $\mathrm{P} 1$ segment of the posterior cerebral artery; Early bifurcation or duplication, fenestration, common trunk with the superior cerebellar artery. Acta Neurochirugica 109:66-71, 1991

4. Dagcinar A, Kaya, AH, Aydin ME, Kopuz C, Senel A, Demir MT, Corumlu V, Celik F, Sam B: The superior cerebellar artery: Anatomic study with review. Neurosurgery Quarterly 17(3):235-240, 2007

5. Gabella G: Cardiovascular system. In: Williams PL (ed), Gray's Anatomy. 38th ed. New York: Churchill Livingstone, 1999:1530-1534

6. Gessaghi VC, Raschi MA, Larreteguy AE, Perazzo CA: Influence of arterial geometry on a model for growth rate of atheromas. Journal of Physics: Conference Series 90: 012046, 2007 
7. Gunnal SA, Farooqui MS, Wabale RN: Anatomical variations of the circulus arteriosus in cadaveric human brains. Hindawi Publishing Corporation Neurology Research International 2014; Article ID 687281, 16. http://dx.doi. org/10.1155/2014/687281

8. Hosapatna M, D'Souza AS, Pallavi, Sumalatha S: Human cadaveric study of the morphology of the basilar artery. Singapore Med J 53(11): 760-763, 2012

9. Ingebrigtsen $\mathrm{T}$, Morgan $\mathrm{MK}$, Faulder $\mathrm{K}$, Ingebrigtsen $\mathrm{L}$, Sparr T, Schirmer H: Bifurcation geometry and the presence of cerebral artery aneurysms. Journal of Neurosurgery 101(1):108-113,2004

10. Kamath S: A study of dimensions of the basilar artery in South Indian subjects. J Anat Society of India 28:45-64, 1979

11. Lasjaunias P, Berenstein A, Ter Brugge KG: Craniocervical junction: Arterial supply to the posterior fossa central nervous system. In: Lasjaunias P, Berenstein A, Ter Brugge KG (eds), Surgical Neuroangiography. 1. Clinical Vascular Anatomy and Variations. Berlin: Springer-Verlag, 2001:224-260

12. McCullough AW: Some anomalies of the cerebral arterial circle of Willis and related vessels. Anat Rec 142:537-543, 1962

13. Ogeng'o JA, Olabu BO, Obimbo MM, Sinkeet SR, Inyimili MI: Variant termination of basilar artery in a black Kenyan population. J Morphol Sci 29(2): 91-93, 2012
14. Okahara M, Kiyosue $H$, Mori $H$, Janove $S$, Samou M, Nagatomi $\mathrm{H}$ : Anatomical variations of the cerebral arteries and their embryology: A pictorial review. Eur Radiol 12(10):2548-2561, 2002

15. Padget $\mathrm{DH}$ : The development of the cranial arteries in the human embryo. Contrib Embryol 32:205-261, 1948

16. Padmavathi G, Rajeshwari T, Niranjana Murthy KV: Study of the variations in the origin \& termination of basilar artery. Anatomica Karnataka 5:54-59, 2011

17. Saeki N, Rhoton AL Jr: Anatomy of posterior circle of Willis. J Neurosurg 46:564-578, 1977

18. Standring S: Gray's Anatomy. 39th ed. Edinburgh: Elsevier Churchill Livingstone, 2005:300

19. Uchino A, Sawada A, Takase Y, Kudo S: Variations of the superior cerebellar artery: MR angiographic demonstration. Radiation Medicine 21(6):235-238, 2003

20. Vasovic L, Jovanovic I, Ugrenovic S, Stojanov D, Radovanovic Z: Basilar bifurcation: A comparison of prenatal and postnatal cases. Neuroanatomy 7:66-71, 2008 